\title{
PEDRO DE BETANCURT, PEDAGOGO Y MAESTRO EN GUATEMALA. UN PROYECTO EDUCATIVO POPULAR EN EL SIGLO XVII
}

Teresa González Pérez

\begin{abstract}
RESUMEN
Pretendemos esbozar la obra de Pedro de Betancurt, fundador de la primera Orden Religiosa en América, que dedico su vida a la atención a los demás. Originario de las Islas Canarias, con apenas recursos volcó sus energías en un proyecto educativo y sanitario en Guatemala colonial. Rompiendo con la tradición fue precursor de la pedagogía y la sanidad en una ciudad marcada por una amalgama étnica discriminada. Fundó la primera escuela popular para niños, niñas y adultos, en las que admitía a todos sin distinción, así tenían cabida mestizos, indios y negros en un entorno de grandes desigualdades, de enormes diferencias sociales, económicas y culturales. Con apenas conocimientos y una rudimentaria instrucción, fue capaz de poner en práctica unas ideas pedagógicas innovadoras respetando la diversidad étnica y cultural. Siguiendo criterios educativos modernos, se adelantó a los tiempos aplicando métodos pedagógicos nuevos, inimaginables para el siglo XVII.
\end{abstract}

PALABRAS CLAVE: Educación popular. Niños pobres. Diversidad étnica. Orden religiosa. Pedagogía moderna.

\footnotetext{
Catedrática da Escola Universitária, Doutora em História pela Universidade de La Laguna e Professora da Faculdade de Educação da Universidade de La Laguna (Espanha). E-mail: teregonz@ull.es
} 


\section{RÉSUMÉ}

Nous désirons évoquer l'oeuvre de Pedro de Betancurt, fondateur de la première Ordre Religieuse en Amérique; homme qui avait offert sa vie à aider l'autrui. D'origine canarien, avec trés peu de recours, il renverse son énérgie en faveur d'un projet éducatif et sanitaire au Guatemala colonial; la pédagogie et la santé marquent sa rupture avec la tradition dans une cité marquée par une amalgame éthnique discriminée. Il fut le fondateur de la première école populaire pour enfants: garçons et filles, ainsi que pour les adultes, école où il accepta à tout le monde sans distinction; c'est ainsi qu'il y avait des métis, des indiens et des noirs dans un lieu d'énormes inégalités, de grandes différences sociales, économiques et culturelles. Sans avoir de grandes connaissances et avec une formation rudimentaire, il fut capable de mettre sur pied des idées pédagogiques innovatrices tout en respectant la diversité éthnique et culturelles. Selon les nouveaux critéres éducatifs, il a pu s'avancer aux temps modérnes en appliquant des méthodes pédagogiques, inimaginables au XVII siècle.

MOTS CLÉS: Éducation populaire. Enfants pauvres. Divérsité éthnique. Ordre Religieuse. Pédagogie nouvelle.

\section{INTRODUCCIÓN}

En estas líneas pretendemos esbozar la figura de Pedro de Betancurt, fundador de la primera Orden Religiosa en América, que dedico su vida a la atención a los demás. Originario de las Islas Canarias, con apenas recursos volcó sus energías en un proyecto educativo y sanitario en Guatemala, rompiendo con la tradición fue precursor de la pedagogía y la sanidad en una ciudad marcada por una amalgama étnica discriminada. No en vano fundó la primera escuela popular para niños, niñas y adultos, en las que admitía a todos sin distinción, así tenían cabida mestizos, indios y negros en un entorno de grandes desigualdades, de enormes diferencias

Educ. e Filos., Uberlândia, v. 22, n. 43, p. 161-182, jan./jun. 2008. 
sociales, económicas y culturales. Con apenas conocimientos y una rudimentaria instrucción, Pedro de Betancurt fue capaz de poner en práctica unas ideas pedagógicas innovadoras respetando la diversidad étnica y cultural (GONZÁLEZ PÉREZ, 2003).

Terciario del Convento de San Francisco, ejemplarizando la vida de Jesucristo, denominó su obra "Belén" recordando la primera posada de Jesús de Nazaret. El 28 de febrero de 1658 fundo la Casa de Belén, el hogar para los sin techo, asilo para ancianos, huérfanos, escuela de primeras letras y lugar para la catequesis. Se dedicó a la educación, a la sanidad y apostolado. Visitó cárceles, hospitales, casas de pobres, atendió a los emigrantes sin trabajo, a niños, jóvenes y mujeres descarriadas. Proyectó la formación religiosa y la instrucción para niños y niñas siguiendo criterios educativos modernos. Llevó el consuelo y solucionó problemas de los afligidos, estableció servicios sociales avanzados y se adelantó a los tiempos aplicando métodos pedagógicos nuevos, hechos inimaginables para el siglo XVII.

La memoria de José de Betancurt y la Orden de Belén permanece viva; sus herederos, la han agrandado a través de los siglos, y su obra reconocida por las generaciones que le sucedieron. Igualmente, la jerarquía eclesiástica ha valorado sus acciones. De manera que el 25 de julio de 1771, el papa Clemente XIV promulgó el decreto de Venerable. Casi dos siglos más tarde, en 1960 se inició el movimiento probeatificación, proceso largo que culminó el 22 de junio de 1980 cuando el papa Juan Pablo II declara, en la Basílica de San Pedro en Roma, Beato al Hermano Pedro. En 1988 en la diócesis de San Cristóbal de La Laguna (Tenerife) comienza la instrucción para la canonización, por la curación milagrosa de un niño tinerfeño afectado de cáncer y cuya familia era muy devota. Numerosos milagros lo condujeron a la santificación, cientos de exvotos en la cueva del Hermano Pedro en el Médano (Tenerife) y en Guatemala testimonian la fe de sus seguidores y las curaciones milagrosas. En su tercera visita pastoral a Guatemala, el día 30 de julio de 2002, el papa Juan Pablo II canonizó al Santo Hermano Pedro de San José de Betancurt. 


\section{ALGUNOS DATOS BIOGRÁFICOS}

Pedro de San José de Betancurt (1626-1667) procedía de las Islas Canarias, natural del pueblo de Vilaflor (en la comarca sur de la isla de Tenerife), era hijo de una familia sencilla y devota (ROSA, 1954). Según los cronistas poseían pocos recursos económicos y culturales, hasta el extremo de que su padre era analfabeto y ni siquiera sabía firmar (VÁZQUEZ DE HERRERA, 1962 , p. 11), pero con cierto rango social (LOBO, 1984, p. 4) ${ }^{1}$. Desde niño comenzó la profesión de pastor de cabras (PILÓN, 1996, p. 6), para ayudar a su familia que se había empobrecido a causa de un usurero. Cuidaba los rebaños en la zona de El Médano, lugar de la costa sur; aún, en la actualidad, conserva la cueva donde se refugiaba de los ataques de los piratas ${ }^{2}$ que incursionaban las costas del Archipiélago, y hoy acoge a gran número de fieles en plegarias y rogativas. La educación cristiana recibida en el seno familiar marco su vida, rezaba, hacía penitencias y ayunaba (MURATORI, 2000, p.136). Además era imaginativo y soñador, con mucha

1 El autor escribe que "el modesto recato y cuidadoso estudio con que Pedro esquivó siempre toda alabanza y cauteló toda estimación, echó la llave del silencio a sus labios, para que de ellos no saliese palabra que insinuase lustre en la ascendencia, o nobleza de sangre. Sus obras los acreditaron de generosa. $\mathrm{Y}$ tal testifica que era, un testigo grave y fidedigno, que conoció a sus padres, y asegura que fueron de lo más noble de las Canarias, donde el apellido Betancurt es muy aplaudido, por muy calificado" (LOBO, 1984, p. 4).

2 Las Islas Canarias sufrieron ataques de la piratería y de los corsarios (ingleses y holandeses), que interceptaban los navíos mercantes y galeones que venían de América. Sobre todo, en el siglo XVII los piratas moriscos apresaban a los pescadores y en los desembarcos arrasaban las islas, se adentraban en las zonas costeras a robar ganado y para cautivar a sus pobladores. Por ejemplo, en 1618 hubo una invasión turca, y en la isla de Lanzarote incendiaron su capital, se apoderaron de un importante botín y apresaron a mil personas (hombres y mujeres). Muchos canarios estuvieron cautivos en Africa, algunos de los cuales pudieron ser rescatados, a través de diversas gestiones de religiosos, autoridades o familiares. Ante estos acontecimientos, en 1626, la corona española nombró capitanes generales para el archipiélago, con el encargo de fortificar las ciudades y mejorar las milicias para la vigilancia de las costas (RUMEU DE ARMAS, 2001).

Educ. e Filos., Uberlândia, v. 22, n. 43, p. 161-182, jan./jun. 2008. 
riqueza espiritual, hecho que contrastaba con la educación recibida. Tal como escribe Damián Muratori:

la rígida educación recibida de sus padres engendró en él una doble vertiente: la del respeto y sumisión libre, a veces formal a las figuras de autoridad y un espíritu de total autonomía. Actitudes estas que Pedro se esforzó de integrar y elevar espiritualmente... la relación con los padres había sido difícil por su educación rígida e impositiva. Aunque fuesen personas muy religiosas y caritativas, con los hijos eran muy exigentes, imponiéndoles sus propios criterios éticos y espirituales. El padre con su austeridad de asceta, había desatendido no poco la relación con los hijos, mientras que la madre los controlaba constantemente y tomaba decisiones por ellos... (MURATORI, 2000, p. 49-50).

Bajo la tutela familiar, la vida de Pedro de Betancurt transcurría trabajando, como buena parte de los jóvenes de la época pero con ilusiones distintas. Ocupado en cuidar el rebaño, su mente volaba en busca de otras experiencias. Su madre pretendía que se casara con una joven honesta, a pesar de no había mostrado ningún interés hacia el matrimonio. Sin embargo, la visita de un sacerdote, con parentesco familiar, que se hallaba de misionero en Indias, despertó la piedad cristiana y junto a los consejos prodigados le sirvieron para guiarle en la toma de decisión. El referido misionero le decía:

Aprende letras, Pedrito, para que le sirvas a Dios en el estado eclesiástico. Por lo que a mi atañe y en cuanto me sea posible, he de favorecerte y, además te espero en Indias... (MESA, 1980, p. 23).

De manera que deseoso de conocer otros horizontes, quiso poner otro rumbo a su existencia y dejar al margen los propósitos familiares, de casarse y formar una familia. Emprendió el camino a América guiado por el entusiasmo de ayudar al prójimo. Este religioso más conocido como Hermano Pedro, era una persona sencilla, poca instruida, nada sabía del esplendor del movimiento social-cristiano, ni de la floreciente vida espiritual y cultural de 
aquel momento. Aislado en su entorno geográfico, sin recursos materiales, culturales o humanos, poseía una preparación muy rudimentaria, pero su precaria instrucción la superaba con creces su devoción cristiana y la entrega a los más necesitados. Según indican algunos historiadores aprendió las primeras letras en el convento agustino de Vilaflor, y probablemente, también, aquí iniciara su vocación religiosa. En Canarias las órdenes religiosas resolvieron las insuficiencias educativas, atendiendo la enseñanza en los lugares donde se asentaron (GONZÁLEZ PÉREZ, 2002, p. 478-479). Al decir de Francisco $\mathrm{M}^{\mathrm{a}}$ de León:

desprovistas en un principio estas islas de escuelas públicas, y de colegios o establecimientos en que se aprendiesen los elementos del saber, los conventos, fueron, durante siglos, los únicos puntos en que se adquiría la instrucción (LEÓN Y XUÁREZ DE LA GUARDIA, 1976, p. 176).

Ante aquella realidad educativa y cultural, sabiendo de la infraescolaridad y de que la comarca sureña de la isla estaba alejada y mal comunicada, resulta obvio que Pedro de Betancurt, casi ignorante, no tuvo contacto con el reducido movimiento cultural ni con la minoría intelectual isleña que residía en las zonas urbanas y capitalina del norte de Tenerife (MILLARES TORRES, 1977, p. 303). El 18 de septiembre de 1649 salió en secreto de su casa hasta el puerto de Santa Cruz de Tenerife, y embarcó rumbo a Cuba. Después de una sinuosa y larga travesía, llegó a La Habana y se alojó en casa de un clérigo de origen tinerfeño. De su estancia en Cuba se conocen pocos datos, se sabe que aprendió el oficio de tejedor (MURATORI, 2000, p. 15), ${ }^{3}$ además de significarse en aquella isla, a juzgar por el nombre de un municipio de la provincia de Matanzas y el de un centro de enseñanza, ambos rotulados

3 En unos cuadernillos, el propio Pedro de Betancurt anotó: "Memoria de cuando me puse a oficio de tejedor, a 4 de septiembre de 1650 años. Memoria de lo que boi dando a Gerónimo Juáres mi maestro, por enseñarme a tejer: me lleba dies pesos. A cuenta de esto le di 20 i 2 de disiembre 3 reales, que compro de miel. Más 10 i 6 de disiembre le di un peso cuando me bino a ver".

Educ. e Filos., Uberlândia, v. 22, n. 43, p. 161-182, jan./jun. 2008. 
Pedro de Betancurt (PILÓN, 1996, p. 9). Más tarde, supo que un barco salía con destino a Puerto Trujillo, en Honduras, y trata con el capitán su embarque, a cambio de realizar trabajos a bordo en el buque. Según relata Marta Pilón escuchó a unos comerciantes referirse a Guatemala, nunca había oído ese nombre, pero desde ese momento sintió la llamada del lugar:

¿Cómo se llama esa ciudad? Y al oír de nuevo el nombre de Guatemala dijo: 'A esa ciudad quiero ir, porque con interior júbilo y superior fuerza me siento animado a caminar a ella, luego que he oído nombrarla, siento así que esta es la primera vez que oigo su nombre'. (PILÓN, 1996, p. 8).

Desde que salió de Tenerife hasta llegar a Guatemala tardó un año y cinco meses, pues como hemos referido, estuvo primero en Cuba y Honduras; desde este último lugar marchó a pie hasta Guatemala. El 18 de febrero de 1651 llegó a tierras guatemaltecas, su tierra prometida, contaba 25 años, aquí vivió hasta su fallecimiento, como el mismo había replicado "Aquí he de vivir y morir" (GARCÍA DE LA CONCEPCIÓN, 1956, p. 154). Santiago de los Caballeros fue el lugar donde durante 16 años plasmó su obra y se consagró en el auxilio de los desfavorecidos.

PRIMEROS AÑOS EN GUATEMALA. FUNDACION DE LA ORDEN DE BELÉN

Pedro de Betancurt después de una intensa ruta arribó exhausto y enfermo. Su llegada a la ciudad de Santiago de los Caballeros coincidió con un terremoto que asoló la ciudad, los temblores se sucedieron hasta el 13 de abril dejando inmensos daños materiales y numerosos heridos. Allí fue atendido en el Hospital Real de Santiago que regentaba la Orden de San Juan de Dios, en el cual se acogía a la gente humilde, hasta que recobró la salud. Durante su periodo de convalecencia conoció a Juan de Uceda y a Antonio Lorenzo de Betancur "que al enterarse del enfermo de su mismo apellido, recién llegado de la Madre España, se apresuró a conocerlo y agasajarlo" (MESA, 1980, p. 50). Juan de Uceda lo acompañó al 
convento de San Francisco porque quería confesarse, allí entabló relación con el sacerdote Fernando Espino, cuya familia paterna procedía de Tenerife y había sido maestro de novicios. El referido religioso franciscano le ayudó e influyó en su destino, ya que lo encaminó a estudiar:

le mandó que estudiase, y a pocas líneas de allí comenzó a estudiar y fue al Colegio de la Compañía de Jesús y comenzó a estudiar, por ruegos de dicho padre (VẢZQUEZ DE HERRERA, 1962, p. 19-20).

También, el padre Fernando Espino, lo recomendó para que trabajara en un taller de tejedor. De este modo, durante tres años (1651-1652-1653) estuvo trabajando en el obraje de urdir lanas de Pedro de Armengol. De su buena relación con la familia Armengol, mantuvo estrecha amistad con el hijo del dueño de la fábrica, hasta el extremo que le ayudaba a estudiar, así como para que mejorara la caligrafía mandándole a copiar textos (MESA, 1980, p. 56). Pedro de Armengol era estudiante de Teología y le prestaba libros para que practicara la lectura, aprendiera gramática y memorizara contenidos (VÁZQUEZ DE HERRERA, 1962, p. 21). El aprendizaje era difícil para Pedro de Betancurt, tenía dificultades para estudiar latín, las declinaciones le resultaban muy complicadas y apenas progresaba en los conocimientos. Sin embargo, no tuvo dificultad en asimilar las materias espirituales, demostró una facilidad suma para la teología (VÁZQUEZ DE HERRERA, 1962, p. 22).

Los comienzos, igual que su vida, fueron humildes pero embargados por su amor a los demás. En Santiago de los Caballeros (Guatemala) se instaló en una casa cerca de la iglesia de $\mathrm{N}^{\mathrm{a}} \mathrm{S}^{\mathrm{a}}$ de la Santa Cruz, regida por la Orden Dominica. Después fabricó una pequeña casita, con techo de paja, para acoger y adoctrinar a los niños y enfermos, al que llamó Hospital de Belén. Se considera el primer hospital de convalecientes del mundo y la primera enferma fue una anciana de color, la primera y única mujer hasta que se fundara la rama femenina, porque era un hospital creado para hombres. Así en 1653, bajo la regla de San Agustín, fundó la Orden de los Betlhemitas o Betlemitas en la ciudad de Santiago de los

Educ. e Filos., Uberlândia, v. 22, n. 43, p. 161-182, jan./jun. 2008. 
Caballeros con el propósito de ayudar a los enfermos y a la infancia marginada, fundación de carácter americano, y la única durante siglos. Pronto su objetivo se canalizó hacia la enseñanza de estos niños, alternando las actividades escolares con las caritativas. No restringió su labor al marco educativo, enseñaba a los niños pero también velaba por sus necesidades primarias -vestido, calzado, alimento- por este motivo ejercía también la caridad para aliviar sus necesidades vitales, incluso pedía para ellos ropas y enseres. Se revela como protector de los excluidos y oprimidos: los indios, negros y mestizos que sufren el abuso laboral y el trato inhumano, los emigrantes, los niños abandonados y huérfanos, en suma, de los cautivos de la miseria.

En la Guatemala colonial que conoció Hermano Pedro la sociedad estaba jerarquizada y el papel de la iglesia trascendía del meramente espiritual. La iglesia introductora de negocios importantes generadores de ingresos, con múltiples propiedades, era fuente de riqueza y económicamente disponía de elevados ingresos provenientes de diversas actividades; $y$, tanto a nivel agropecuario como comercial, tuvo un protagonismo singular. El auge económico experimentado con el cultivo del añil o índigo coincide con los años en los que se establece la Orden de Belén. Los colonos aprovechaban y explotaban la mano de obra indígena, negra y mestiza, sectores marginados que se ocupaba de los trabajos duros realizados en pésimas condiciones laborales, y a los que prestó especial atención este humilde y caritativo isleño. En esta centuria olvidada y decadente, en la América hispana aparecieron los fenómenos de degradación social, efecto de la decadencia española que enviaba gente "cada vez más inmoral e incompetente" (DOMINGUEZ ORTIZ, 1988, p. 418). El espíritu de Fray Bartolomé de las Casas se había relajado y el compromiso se había suavizado, la iglesia y la monarquía española se inclinaron más a favor de las clases dominantes que a luchar por la causa de los indígenas (DOMINGUEZ ORTIZ, 1988, p. 444). El mundo colonial fue un mundo lleno de injusticias y abusos, de antagonismos sociales (VICENS VIVES, 1988, p. 446). El panorama étnico fue cada vez más complejo y diverso, un proceso que a lo 
largo del XVII adquirió un desarrollo progresivo del hibridismo. Además, al incrementarse el número de mujeres españolas y/o criollas los matrimonios mixtos descendieron, cada vez su unían con personas de su misma clase y origen, se fue acentuando el orgullo de la raza blanca, que fue desplazando y despreciando a los híbridos (VICENS VIVES, 1988, p. 447). Las categorías étnicas marcaban diferencias, se incrementaron los grupos sociales desheredados que no tenían reconocimiento ni derechos.

Esta situación no contó con el beneplácito de Pedro de Betancurt, no se dejó guiar por la actuación de la jerarquía eclesiástica ni sociopolítica, trató de paliar la injusticia con su labor humanitaria y de atención a los otros. Su compromiso se fue extendiendo, sin recursos, sin prestigio, carentes de toda ciencia, y sin contar con el apoyo de otras Ordenes Religiosas establecidas. A veces recibió ayudas económicas, este hecho junto al aumento de los acogidos, le animan a iniciar la construcción de un hospital junto a aquellas casitas iniciales. Con las limosnas logró edificar un hospital, en cuya construcción trabajó como un obrero, para acoger a los enfermos convalecientes que eran desalojados de los hospitales por falta de espacio. Todos tenían cabida en su centro, y así lo han seguido practicando sus seguidores. Los bethlemitas hacen un cuarto voto, el de la Hospitalidad, por el que se obligan a acoger a todo enfermo (independientemente del tipo de enfermedad) de cualquier condición o raza. El primer hospital disponía de enfermería, habitaciones para los hermanos, aulas de clase, patios y galerías.

Esta Orden se extendió por toda la América hispana sorteando todo tipo de dificultades. Tras el fallecimiento de Pedro de Betancurt le sucedió Fray Rodrigo de la Cruz, que había sido gobernador de Honduras y ostentaba el título nobiliario de marqués. A los cuatro meses de tomar el hábito fue nombrado Padre de los Hermanos de Belén, cargo que mantuvo durante cincuenta años. La entrega de los hermanos, sucesores de su testimonio evangélico, y los donativos que recibieron les permitió crear nuevas y reconocidas fundaciones: obras socioculturales, hospitales, escuelas y noviciados se multiplicaron con rapidez. Con el doble objetivo, la atención a los

Educ. e Filos., Uberlândia, v. 22, n. 43, p. 161-182, jan./jun. 2008. 
enfermos y la enseñanza a los niños de condición humilde, la congregación Betlhemita -que además era la única Orden religiosa de origen americano- fue extendiendo su labor por todo el Continente. A los veinte años de su muerte se habían fundado once hospitales, continuó su esplendor en el siglo XVIII, en 1710 habían fundado dieciocho hospitales, tres años más tarde ya tenían veintiuno (diez en México y once en Perú). Junto a estos centros funcionaban escuelas que atendían numerosos alumnos, escuelas anexas a los hospitales que cumplían con una función instructiva y catequética, por ejemplo en la escuela de Belén de La Habana recibían instrucción gratuita más de quinientos niños pobres. Esta Orden se mantuvo en el tiempo, permaneció en el siglo XIX pese a los decretos de las Cortes de Cádiz.

En Tenerife durante el siglo XVIII se intentó establecer la Orden en la patria del fundador, pero intrigas y recelos frustraron la obra, pese a que se necesitaba con urgencia un hospital de convalecientes y escuelas. Pensaron en varios lugares: Vilaflor, Santa Cruz y la Orotava. Se instalaron en el Hospital de San Sebastián de Santa Cruz de Tenerife, fundaron una escuela con asistencia de más de trescientos niños, pero la falta de dinero junto con las rivalidades eclesiásticas y las medidas secularizadoras les obligó al cierre (GONZÁLEZ PÉREZ, 2002, p. 482).

\section{INTERÉS POR EL APRENDIZAJE}

Los documentos de la época refieren el empeño por aprender de Pedro de Betancur, así como las penitencias y sacrificios a las que voluntariamente se sometió para asimilar los conocimientos con nulo resultado. Se esforzó en prepararse como clérigo e instruirse en la lengua latina, pero no pudo aprender porque el latín se le resistió. Es suficientemente conocido que el Hermano Pedro intentó estudiar y formarse en el sacerdocio misionero, pero sus aptitudes para el estudio eran nefastas. Su memoria le traicionaba, y pese a las penitencias y oraciones no consiguió aprender. Sus biógrafos refieren que sus compañeros y maestros le admiraban por su aplicación:

Educ. e Filos., Uberlândia, v. 22, n. 43, p. 161-182, jan./jun. 2008 
En todas partes se le veía con su libro en las manos. Del obraje, distante una media legua, venía cada mañana a pie hasta el estudio con tiempo suficiente para oír misa de siete. Y en los ratos libres o en días festivos, después de sus obras de caridad y de sus ratos de doctrina a los esclavos detenidos en la fábrica, sus compañeros lo veían pasearse por el campo vecino al Hospital de San Lázaro, tratando de grabarse los preceptos gramaticales, las áridas declinaciones y conjugaciones (MESA, 991, p. 61).

Se dedicaba de forma obstinada al estudio, se esforzaba aprovechando sus ratos libres, pero la gramática, las declinaciones y las conjugaciones se le resistían y la memoria le fallaba. Incluso cuando se repasaba la lección semanal, actividad que realizaban los sábados siguiendo el modelo de la pedagogía jesuítica, creyendo que la sabía no recordaba nada. No perdía la ilusión en sus clases, aunque era el alumno de más edad era el que menos aprendía, captaba las nociones y las olvidaba inmediatamente. Su preceptor era Juan de la Cruz, y la frustración de maestro y discípulo no podía ser mayor a pesar del empeño de ambos. El propio Pedro de Betancurt sugería a su maestro que le sancionara:

Padre, tómeme V.R. la lección y deme castigo de palmetas, como a los niños, si ve que no aprovecho (MESA, 1991, p. 61.)

En este sentido se aplicó la pedagogía de la época "la letra con sangre entra", una práctica metodológica por la que se decantó, y pedía al maestro que le castigara igual que a los niños cuando no sabía la lección. Además el mismo se autoimponía castigos (algunos de sus muchos azotes se los propinó en devoción de $\mathrm{N}^{\mathrm{a}} \mathrm{S}^{\mathrm{a}}$ de Candelaria), aprovechando su irrefrenable propensión a la "mortificación sangrienta". Podemos señalar como ejemplo una de sus promesas para alcanzar la sabiduría:

20 de enero de 1654 hasta 3 de febrero propongo: lo primero, confesión y comunión; lo segundo, ocupar todas las horas de los días siguientes: tercero, cinco días de cilicio; lo cuarto, tres horas de estudio cada día, en honor de la Purificación de Nuestra Señora. (MURATORI, 2000, p. 53)

Educ. e Filos., Uberlândia, v. 22, n. 43, p. 161-182, jan./jun. 2008. 
Pensaba que a través del dolor físico se predisponía para el aprendizaje, y constituía una forma adecuada de asimilar los conocimientos, como si suavizara la mente para que dejara paso a la cultura letrada. Sin embargo, su obstinación y empeño por instruirse no consiguieron desafiar su ignorancia ni fortalecer su memoria.

\section{LA ENSEÑANZA DE LOS POBRES: UN PROYECTO DE EDUCACION NO FORMAL}

En Guatemala, en tiempos de la colonia, la enseñanza era un bien exclusivo para los españoles y sus descendientes. La otra infancia no tenía derecho al aprendizaje, ni siquiera a conocer la lectura y la escritura. Adquirir la cultura letrada tenía un carácter elitista y los sectores populares permanecían ajenos al saber, sólo adquirían los conocimientos que les transmitía su familia.

La enseñanza de los indígenas no preocupó mucho, cuando al contrario, se embruteció aquella raza bajo el hierro candente, el látigo y el alcohol y bajo el peso de los trabajos más brutales. En cambio, la escuela destinada para los hijos de los españoles, fundada por el Obispo Marroquín, llamó la atención del monarca español que por Cédula del 21 de mayo de 1553, fue recomendada para que le protegiera por las autoridades coloniales (PILÓN, 1996, p. 47).

Las noticias educativas son difusas y existen indicios de que cerca de la iglesia de San Pedro había un colegio para indios. También disponemos del dato que apunta que, por Real Cédula de 3 de junio de 1553 se ordenó establecer una escuela para niños mestizos, pero no se posee información sobre si llegó a constituirse (GUÍA, 1968).

Para lograr sus propósitos, el tinerfeño Pedro de Betancurt, tuvo que sortear muchos obstáculos, pero las dificultades no le arredraron y crecía la ilusión por hacer realidad su objetivo: fundar un instituto que cumpliera múltiples funciones: religiosas, educativas, sanitarias y caritativas (VÁZQUEZ DE HERRERA, 
1962, p. 77). ${ }^{4}$ Las dificultades que experimentó para el aprendizaje no obstaculizaron su ideario educativo, al contrario se vio reforzado con un proyecto pedagógico intercultural pensado tanto para los niños como las niñas. Todos y todas tenían cabida, sin distinción de raza o etnia. A la escuela podían concurrir blancos, indios, mestizos, negros cualquiera que fuera su condición. De este modo, contagiado por esa inquietud de redimir a los pobres, enseñaba y adoctrinaba personalmente en su escuela de primeras letras a sus discípulos, en una acción educativa que se encuadra perfectamente dentro de la educación no formal. Se empeñó en acoger a los niños, niñas y adultos que quisieran aprender la doctrina, la kmectura y escritura así como algunos rudimentos de aritmética. La obra creada se conocía como la Casita de la Virgen o la Casita del Hermano Pedro, durante la noche servía de dormitorio, pero de día las camas se desarmaban para reutilizarlas a modo de bancos escolares para que los niños y niñas pudieran aplicarse al aprendizaje. Las niñas excluidas de los saberes fuera del hogar, reducidos casi exclusivamente a conocimientos de tipo doméstico y religioso, tuvieron una oportunidad de aprendizaje, a pesar de que en Canarias (GONZÁLEZ PÉREZ, 1998b; 1998a, p. 385-401) tampoco estaban escolarizadas no dudó de admitirlas en su escuela. Si bien, con las connotaciones propias de aquel entonces y cuidando de la moral, separaba los horarios de clases y evitaba la asistencia conjunta de ambos sexos.

su cuidado a enseñar niñas: pero, porque estas no concurriesen con varones, cuya mezcla es en todas edades peligrosa, les señalaba horas distintas: de modo que, las niñas eran doctrinadas por la

4 Este autor refiere, al respecto, que fundó "un nuevo instituto hospitalario, que tenga por constitución desde su primera fundación el tener escuela donde sean instruidos en las artes de leer, escribir y contar los niños, e industriados en las obligaciones cristianas. Casa de María Santísima señora nuestra donde por instituto se celebran con tanta solemnidad sus nueve festividades, casa del refugio, hospicio de pobres y forasteros, ejercicio de misericordiosa hospitalidad y con toda propiedad casa de nuestra Señora de los Remedios" (VÁZQUEZ DE HERRERA, 1962, p. 77).

Educ. e Filos., Uberlândia, v. 22, n. 43, p. 161-182, jan./jun. 2008 
mañana, y por la tarde los niños (GARCÍA DE LA CONCEPCIÓN, 1956, p. 177).

En Guatemala los Betlemitas fueron la primera Comunidad que abrió una escuela pública para niños pobres, y emprendió actividades que beneficiaron directamente a los indígenas y mestizos necesitados. No en vano su fundador ha recibido el calificativo de "benefactor de los indios". Si bien en la sociedad guatemalteca los miembros del clero destacaron como las personas más notables y se revelaron a la vez como promotores de la economía, como intelectuales, eruditos y pedagogos, Pedro de Betancurt destacó como maestro de los pobres (GONZÁLEZ PÉREZ, 2003; 1994). No es vano creó la primera escuela de alfabetización para niños y adultos, preocupado por la suerte de los desvalidos. Se interesó por la instrucción de los adultos hasta el extremo de detraer de las limosnas que obtenía una cantidad de dinero y les pagaba para que asistieran a la escuela. Esta era una fórmula de garantizar la enseñanza, porque en las horas que acudían a la escuela no podían ir a trabajar y como quiera que necesitaban ganar dinero para poder subsistir, para que no abandonaran el aprendizaje el Hermano Pedro les abonaba el salario.

Un currículum escolar sencillo conformaba la tarea de la enseñanza elemental: leer, escribir y el catecismo. Los problemas que el mismo sufrió en el aprendizaje no fueron motivo de adversión a la enseñanza, como hemos dicho anteriormente, todo lo contrario, parece que se implicó más y despertó una gran sensibilidad hacia la metodología y la didáctica. No poseía preparación ni cualificación pedagógica y su nivel de instrucción era muy precario, pero fue precursor de la pedagogía contemporánea, de la escuela nueva, persuadido por la enseñanza activa aportó un enfoque distinto a la escolaridad. Así tuvo en cuenta la motivación del alumnado y por ello despertaba su interés amenizando sus clases con canciones y juegos.

Su mentalidad sin preparación pero despierta comprendía el supremo beneficio de la enseñanza... Sabía ponerse al nivel de los discípulos, entrar en íntima comunicación con ellos. No le ayudaba 
menos, para el buen resultado, su alegría. Por intuición puso en práctica un procedimiento que la ciencia pedagógica convertiría más tarde en sistema: el uso del canto en la educación (SOTOHALL, 1935, p. 102).

Pedro de Betancurt, hombre bondadoso y generoso, no recurre al empleo de los severos métodos didácticos que utilizaban en su época, sabía que las actividades lúdicas estimulaban el proceso enseñanza-aprendizaje y evitaban la rutina facilitando el saber a los niños. Innovador y autodidácta que con el desempeño de su tarea se adelantó a su tiempo. Sorprende como empleaba una pedagogía avanzada y, preludiando a Fröbel $^{5}$ con casi dos siglos de antelación, recurrió a la pedagogía del juego, a enseñar de forma jubilosa.

para enseñar usaba maneras sencillas y alegres, contrarias a los métodos severos y de temor proverbiales de esa época; jugaba, danzaba alegremente sonando una pandereta y cantando rimas. Con este método de "enseñar jugando", se adelantó cientos de años a la pedagogía moderna (PILÓN, 1996, p. 20).

Además de la novedosa metodología, hay que reconocerle la no discriminación étnica. Todos los desheredados, los excluidos, encontraron un espacio en la Orden de Belén y el cobijo de su fundador. Para poder entender el alcance de su obra educativa y sanitaria hay que situarse en el contexto del mil seiscientos en la Guatemala colonial. El desarrollo de la población y el progreso de la colonización implicó el aumento del censo infantil, lo cual conllevó al establecimiento de colegios que atendían las ordenes religiosas. La sociedad blanca asistía a colegios privados, eran centros para formar a los hijos de la élite a los que no tenían acceso los pobres. La discriminación social y el sometimiento de estos

5 Friedrich Fröbel (1782-1852) (CUELLAR PÉREZ, 2005), pedagogo alemán inspirado en Pestalozzi que defendía el desarrollo armónico de las facultades y aptitudes naturales de los niños, amparado en una educación con mayor libertad y práctica de juegos.

Educ. e Filos., Uberlândia, v. 22, n. 43, p. 161-182, jan./jun. 2008 
grupos a condiciones pésimas de vida generó el interés de Pedro de Betancurt, por este motivo la escuela que inaugura representó la popularización de la enseñanza, acercar el saber a los desfavorecidos, a los marginados, es decir, a los pobres, blancos, indios, negros o mestizos. Porque en aquella época la educación reforzaba las desigualdades sociales, la marginación y la pobreza conducían (aún conducen) a la exlusión social. En el plano personal la falta de formación y educación no favorecía la integración social. Así, abordaba desde la perspectiva educativa y social, en una acción que comprendía la ayuda económica materializada en el alimento, el vestido y el calzado, la atención a la infancia, o en términos más actuales la asistencia social.

Sorprenden sus esquemas educativos, cuando apenas había recibido formación, y sobre todo considerando que siendo oriundo de las Islas Canarias, un archipiélago de la ultraperiferia hispana, alejado geográficamente de la monarquía y cuyas autoridades desinteresadas no se ocuparon de las cuestiones educativas, donde el analfabetismo y la absoluta carencia de escuelas públicas fue la característica. Donde la segregación sexual y social marcaba las relaciones sociales, estando las mujeres al margen del proceso educativo. Su objetivo era popularizar la enseñanza, rompiendo con la tradición. Así creó una escuela inclusiva, defendiendo una escuela que atendiera a los marginados de la escuela oficial. Defendió la cultura escolar para los menores desvalidos, propagando la alfabetización para los excluidos. De manera que resultó una experiencia pedagógica alternativa al modelo educativo hegemónico.

Pedro de Betancurt, sin darse cuenta, fundó el primer centro de alfabetización popular en Guatemala y probablemente en todo el Nuevo Mundo; por ello, con toda justicia histórica, se le puede llamar el precursor del alfabetismo en América (PILÓN, 1996, p. 20).

El reconocimiento a su labor ha quedado registrada desde hace siglos. Han sido muchos los escritores que han elogiado sus méritos y valorado su quehacer. Como fue el caso de José de Viera y Clavijo, 
insigne historiador, científico y escritor de las Islas Canarias, que plasmó en las páginas de su destacada obra Historia de Canarias la distinguida tarea de los Betlemitas:

una orden tan célebre, fundada por un patriarca canario, y que tiene por ejercicio peculiar la enseñanza de los niños y el cuidado de los enfermos (VIERA Y CLAVIJO, p. 385).

Los seguidores de la Orden del fundador, también continuaron su proyecto pedagógico, y en los lugares que se establecieron fundaron escuelas con semejantes innovaciones didácticas. La impronta pedagógica de Betancurt traspasó fronteras, tanto espaciales como temporales; nada se resistió a la práxis educativa con los desheredados. Según escribe Antonio Bethencourt:

la educación de los niños llevada a cabo en semejante Orden ha redundado en beneficio de todas las ciudades donde se asentaron, ya que los formaban tan magníficamente que muchos Prefectos de otras Ordenes religiosas han salido de estas filas, así como varios preceptores de niños en la ciudad de Méjico (BETHENCOURT MASSIEU, 1965, p. 164).

Para terminar señalar que, igualmente, desde el punto de vista médico, realizó grandes aportaciones careciendo de conocimientos clínicos. De modo que también la sanidad encuentra en él un referente. Tanto la geriatría como las enfermedades infectocontagiosas estuvieron presente en su hospital. Sin duda, una obra sanitaria singular y novedosa, donde había lugar para la diversidad de enfermos rechazados en otros centros médicos, allí siempre eran bien recibidos.

\section{PARA FINALIZAR}

Pedro de Betancourt, un pastor de cabras del municipio sureño de Vilaflor (Tenerife - Islas Canarias) sintió la llamada divina, dejó su tierra y se embarcó con su fe rumbo a América. Llegó primero a

Educ. e Filos., Uberlândia, v. 22, n. 43, p. 161-182, jan./jun. 2008. 
Cuba, desde donde se trasladó a Honduras y desde allí, andando, llegó a su tierra prometida: Guatemala. Propagó la doctrina cristiana y el amor al prójimo, siendo todo un ejemplo de austeridad y sacrificio en la sociedad colonial aquejada de tantos males y desentendida de los problemas de los pobres.

Fundó la Orden de Belén, la primera de origen americano, y se dedicó a la caridad sin distinción de personas, atendía a los enfermos marginados y desheredados tanto adultos como niños. Construyó un hospital y en sus aledaños una escuela, para niños y adultos pobres, con el objetivo de popularizar la enseñanza. Sin embargo su mérito no se circunscribe sólo a la labor de carácter humanitaria, porque también realizó una gran contribución educativa. No en vano fue precursor de la pedagogía contemporánea, su metodología le sitúa en lo más avanzado del pensamiento pedagógico. Innovador en la práxis educativa, empleó metodología novedosa y recurrió al juego como método de enseñanza-aprendizaje anteponiéndose a Fröebel. Pretendía que la cultura penetrara en los desfavorecidos, les animaba al estudio a pesar de las dificultades que él mismo experimentó en el aprendizaje. Aunque carecía de formación específica y poseía poca preparación intelectual, su encomiable labor merece reconocimiento y podemos referirlo como maestro autodidacta. Con una personalidad dotada de habilidades, a modo de sabio natural, con apenas conocimientos, fue capaz de romper la tradición educativa y hacer soñar a los excluidos con otra escuela. Sorprende como Pedro de Betancurt, que vivió el atraso cultural y educativo en Canarias, que no conoció el pensamiento pedagógico europeo ni los movimientos de renovación educativa, fue capaz de ser pionero en la práctica pedagógica en la Guatemala colonial. Un autodidácta que supo llevar, allende los mares, otra escuela. Acogió a las niñas para instruirlas en su escuela, aunque sin apartarse de la segregación sexual; pero cabe resaltar el gesto progresista, al margen de los aprendizajes femeninos que las consagraban como mujeres en aquel entonces.

El Hermano Pedro, Apóstol de Guatemala, es muy conocido y venerado en el continente americano, sobre todo en Centroamérica. 
En cambio, en Canarias la oralidad transmitía de generación en generación las características de su personalidad y su dedicación a los más necesitados. Su humildad y sencillez despertó mucha devoción entre los isleños por los milagros que realizaba, y por la respuesta a las oraciones de los fieles seguidores que acudían a su "cueva" (ubicada en El Médano, costa sur de Tenerife) en rogativas. La fe popular lo mantenía vivo, aunque en las últimas décadas el establecimiento de la Orden en La Laguna (Tenerife) contribuyó a la difusión de su obra. Imágenes, estampas, medallas, oraciones, escritos, artículos y publicaciones diversas se han ocupado de plasmar su labor. Este tinerfeño que transformó en más humanitaria y culta a la sociedad guatemalteca de la segunda mitad del seiscientos, atendiendo a dos grandes demandas sociales aún vigentes en la actualidad: la sanidad y la educación, fue canonizado el pasado 29 de julio de 2002. Se convirtió así en el primer santo Canario y en el primer santo de Centroamérica, su otra patria, ganando popularidad su labor, pero continua siendo el Hermano Pedro, apóstol de los desvalidos y de los ignorados, también maestro de los pobres y marginados.

\section{BIBLIOGRAFIA}

BETHENCOURT MASSIEU, Antonio. Política regalista en Canarias: el fracaso en la instalación de los Betlemitas. En Anuario de Estudios Atlánticos, Madrid-Las Palmas, nº 29, 1965.

GARCÍA DE LA CONCEPCIÓN, José. Historia Belemítica. Vida ejemplar y admirable del Venerable Siervo de Dios, y Padre Pedro de San José de Betancur, fundador Regular del Instituto de Belén. Guatemala: Biblioteca Goathemala de la Sociedad de Geografía e Historia de Guatemala, Vol. XIX, 1956.

GONZÁLEZ PÉREZ, Teresa. Algunas referencias históricas sobre la educación de la mujer en Canarias. En Tebeto XII. Puerto del Rosario: Anuario del Archivo Histórico Insular de Fuerteventura, 1998a.

Educ. e Filos., Uberlândia, v. 22, n. 43, p. 161-182, jan./jun. 2008. 
El Hermano Pedro y el proyecto de educación no formal en Guatemala. II Congreso Iberoamericano de Historia de la Educación Latinoamericana. Brasil: Universidad de Campinas, 1994.

Institucionalización de la enseñanza en Canarias. Ojeada histórica sobre la educación en los siglos XVI y XVII. En Tebeto, XV. Puerto del Rosario: Anuario del Archivo Histórico Insular de Fuerteventura, 2002.

Mujer y Educación en Canarias. Santa Cruz de TenerifeLas Palmas de Gran Canaria: Benchomo-Cabildo Insular, 1998b.

Pedro de Betancurt, maestro de los niños pobres. Congreso Diálogo Fe-Cultura, Tenerife: Centro de Estudios Teológicos-Universidad de La Laguna, 2003.

GUÍA de Antigua Guatemala. Escuelas y Colegios. Guatemala: Sociedad de Geografía e Historia de Guatemala, 1968.

LOBO, Manuel. Relación de la Vida y Virtudes del Venerable Hermano de San José de Betancur. Guatemala, 1984.

MESA, Carlos. Pedro de Betancur. El hombre que fue caridad. 3 ed. Tenerife: Editorial-Imprenta Santa Rita (Granada), 1991.

MILLARES TORRES, Agustín, Historia de Canarias. Tomo III. Las Palmas de Gran Canaria. EDIRCA, 1977.

MURATORI, Damián. Escritos del Beato Hno. Pedro de S. José de Betancur. Transcripción de papeles autógrafos. Roma, 2000.

PILÓN, Marta. El Hermano Pedro un hombre de Dios. Guatemala: Artemis-Edinter, 1996. 
ROSA, Leopoldo. La familia del Hermano Pedro, Revista de Historia de Canarias, $\mathrm{n}^{\circ} 105-108$, Facultad de Filosofía y Letras, Universidad de La Laguna, Tomo XX, 1954.

RUMEU DE ARMAS, Antonio. Canarias y el Atlántico. Piratería y ataques navales. 5 Vol. Santa Cruz de Tenerife: Gobierno de Canarias, 2001.

SOTO-HALL, Máximo. El San Francisco de Asís Americano. Pedro de San José Bethencourt. Buenos Aires: Librería García Santos, 1935.

VÁZQUEZ DE HERRERA, Francisco. Vida y muerte del Venerable Hermano Pedro de San José de Betancur. Ampliaciones a la Relación de la Vida y Virtudes del Venerable Hermano escrita por el R.P. Manuel Lobo, S.J. Guatemala: Lázaro Lamadrid, 1962.

VIERA Y CLAVIJO, José. Historia de Canarias. Tomo II, Santa Cruz de Tenerife: Ediciones Goya, 1978. 